NBER WORKING PAPER SERIES

\title{
INFORMATION ASYMMETRY, INFORMATION PRECISION, AND THE COST OF CAPITAL
}

Richard A. Lambert

Christian Leuz

Robert E. Verrecchia

Working Paper 14881

http://www.nber.org/papers/w14881

\author{
NATIONAL BUREAU OF ECONOMIC RESEARCH \\ 1050 Massachusetts Avenue \\ Cambridge, MA 02138
}

April 2009

The views expressed herein are those of the author(s) and do not necessarily reflect the views of the National Bureau of Economic Research.

NBER working papers are circulated for discussion and comment purposes. They have not been peerreviewed or been subject to the review by the NBER Board of Directors that accompanies official NBER publications.

(C) 2009 by Richard A. Lambert, Christian Leuz, and Robert E. Verrecchia. All rights reserved. Short sections of text, not to exceed two paragraphs, may be quoted without explicit permission provided that full credit, including $(\mathcal{C}$ notice, is given to the source. 
Information Asymmetry, Information Precision, and the Cost of Capital

Richard A. Lambert, Christian Leuz, and Robert E. Verrecchia

NBER Working Paper No. 14881

April 2009

JEL No. G12,G14,G31,M41

\section{ABSTRACT}

The consequences of information differences across investors in capital markets are still much debated. This paper examines the relation between information differences across investors and the cost of capital, and makes three points. First, in models of perfect competition, information differences across investors affect a firm's cost of capital through investors' average information precision, and not information asymmetry per se. Second, the average precision effect of information that is heterogeneously distributed across investors is unlikely to diversify away when there exist many firms whose cash flows covary. Thus, better disclosure can reduce a firm's cost of capital. Third, the precision effect does not give rise to a separate information-risk factor. These points are important to empirical research in accounting and finance, as well as to regulators who debate future disclosure requirements and the consequences of prior requirements such as Regulation Fair Disclosure.

Richard A. Lambert

Wharton School - University of Pennsylvania

3620 Locust Walk

Steinberg-Dietrich Hall

Philadelphia, PA 19104

lambertr@wharton.upenn.edu

Christian Leuz

Graduate School of Business

University of Chicago

5807 S. Woodlawn Avenue

Chicago, IL 60637-1610

and NBER

cleuz@chicagobooth.edu
Robert E. Verrecchia

Wharton School - University of Pennsylvania

Steinberg-Dietrich Hall

3620 Locust Walk

Philadelphia, PA 19104

verrecch@wharton.upenn.edu 


\section{Introduction}

Information differences across investors (or groups of investors) have been a longstanding concern to securities regulators and at the core of U.S. disclosure regulation (e.g., Loss, 1983; Loss and Seligman, 2001). For example, the Securities and Exchange Commission (SEC) recently enacted Regulation Fair Disclosure (Reg FD), which intends to equalize information across investors by preventing companies from making disclosures to select groups of investors and analysts. The SEC (2000) argued that selective disclosure allows "those who were privy to the information beforehand...to make a profit or avoid a loss at the expense of those kept in the dark," and that this practice leads to a loss in investor confidence (see also Levitt, 1998). Particularly, small investors might be unwilling to invest if they fear that insiders gain at their expense; this, in turn, increases firms' cost of capital to the extent that the risk in the economy has to be borne by fewer investors. Similarly, investors might demand a return premium for investing in the capital markets or stocks that exhibit substantial information asymmetry. ${ }^{1}$ Critics of Reg FD argued, however, that it could stifle corporate disclosure and, in turn, increase firms' cost of capital (AIMR, 2001). For example, SEC Commissioner Unger (2000) voted against the proposed regulation because of concerns that it would "most likely reduce the amount of information available to investors...and the quality of the information that would be produced." As this example shows, the consequences of information asymmetry in capital markets, and, in particular, its relation to the amount and precision of information available to investors and the cost of capital, are still much debated.

The issues of whether and how information differences across investors affects

1 For evidence consistent with this notion see, e.g., Amihud and Mendelson (1986), Chordia, et al. (2000), and Easley, et al. (2002). 
prices and the cost of capital cannot be addressed in models of asset pricing that assume that investors have homogeneous beliefs. Examples of such models are the Capital Asset Pricing Model (CAPM), but also a recent model by Lambert, et al. (2007) used to study the effect of accounting disclosure on the cost of capital. Studies that have developed models of capital market equilibria where investors have heterogeneous information have reached different conclusions regarding the effects of information on the cost of capital. For example, Leland (1992) finds that allowing insider trading will, on average, increase stock prices despite the fact that the presence of insiders increases information asymmetry in the economy. Although he does not couch his analysis in terms of cost of capital, higher stock prices on average are tantamount to a decrease in firms' cost of capital. In contrast, O'Hara (2003), Easley and O'Hara (2004) and Hughes, et al. (2007) conclude that information asymmetry increases firms' cost of capital. Specifically, Easley and O'Hara (2004) analyze differences in the composition of information between public and private information. They argue that less informed traders recognize they are at an information disadvantage, and hold fewer assets as a consequence. This drives down the price of securities with high degrees of private information and hence information asymmetry, thereby increasing the cost of capital for these firms. They conclude that "private information thus induces a new form of systematic risk, and in equilibrium investors require compensation for it." Hughes, et al. (2007) argue that information asymmetries increase cost of capital by increasing factor risk premiums. Wang (1993) finds that increasing the percentage of informed investors in the economy lowers the cost of capital. As Wang notes, the information structures he analyzes affects both information asymmetry and average precision. As such, Wang concludes that his results are attributable to the joint effect of both. 
Our paper explores the relation between information differences across investors, information precision, and the cost of capital. Similar to Admati (1985), and in contrast to models of trade commonly found in the literature, we conduct our analysis in an economy with multiple firms whose cash flows covary. We define cost of capital as the difference between beginning-of-period stock price and the expected end-ofperiod cash flow. We define average precision as the quality of investors' information about firms' cash flows on average, and measure information asymmetry based on the differences in the quality, or precision, in information across investors.

We show that when capital markets are characterized by perfect competition among investors (as all of the aforementioned models and many others assume), equilibrium prices are a function of two features of the economy's information structure only: 1) individual investors' precision-weighted-average assessment of firms' expected end-of-period cash flows; and 2) their average, equilibrium precision matrix (i.e., the inverse of the covariance matrix) of the distribution of firms' end-of-period cash flows. The latter feature is the key determinant of the discount in prices relative to the expected value of cash flows. In other words, the expected return on a firm's stock price, and therefore its cost of capital, is directly related to investors' average precision matrix. The extent to which investors' precision matrices deviate from this average, however, does not matter. In particular, information asymmetry does not affect the discount for risk, holding average precision constant. This is true whether information asymmetry is defined in terms of investors' equilibrium precisions (which includes any inference they make from price) or in terms of their exogenous information (i.e., their priors, public information, and private information).

Thus, we show that, in perfect competition models, there is no separate, systematic risk factor in price that stems from private information. Less informed investors 
choose to hold fewer shares in firms where their uncertainty is greatest, not where information asymmetry is greatest. In fact, an investor's degree of uncertainty decreases when other investors acquire more information (even when it is private), because this information gets communicated (partially) through price when investors condition their expectations over price in determining their demand (e.g., Grossman and Stiglitz, 1980; Leland, 1992). We show that, as a result, increasing information asymmetry actually decreases the firm's cost of capital, as long as the change in information structure increases average precision.

Another contribution of our paper is that it extends the analysis of information differences on the cost of capital to a multiple-firm economy where firms' cash flows covary. This allows us to make the distinction between diversifiable and nondiversifiable risk, and to ask the important question of whether a firm can affect its cost of capital by disclosing additional information in large economies where investors hold diversified portfolios. We extend two commonly used non-homogeneous information structures in the extant rational expectations (RE) literature to a multi-firm economy: one where investors have diverse information, as in Grossman (1976) and Kim and Verrecchia (1991), and one where one group of investors has superior information to another group, as in Grossman and Stiglitz (1980), Easley and O'Hara (2004) and Hughes, et al. (2007). We show that what matters in determining the cost of capital in a multi-firm economy is the average precision matrix of information across investors. Analogous to the CAPM, information differences across investors that depend solely on the variance of a firm's cash flows diversify away as the economy gets large. Thus, the off-diagonal elements of investors' precision matrices play a critical role toward ensuring that a firm's cost of capital does not reduce to the risk-free rate. We show that, with non-zero off-diagonal elements in the precision 
matrices, information disclosure by a firm reduces the discount for risk that investors associate with holding shares in that firm. These results extend the estimation risk literature (e.g., Brown, 1979; Barry and Brown, 1984, 1985) as well as recent work by Lambert, et al. (2007), which assumes all investors have homogeneous information.

Aside from its theoretical contributions, our paper also has several important implications for empirical studies. First, the paper shows that it is important to distinguish between information asymmetry and information precision. A shift in information asymmetry can appear to affect the cost of capital, but this effect may occur because the average precision of information is changing simultaneously. Thus, to isolate the effect of information asymmetry, one has to control for changes in information precision. That said, many changes to a firm's information environment (e.g., improved accounting standards, better disclosure, more analyst following, etc.) that affect the average precision in the economy are likely also to change the degree of information asymmetry and vice versa. As a result, it is difficult to differentiate the effects empirically. Thus, empirical studies should exercise care in choosing their information constructs. It may also be interesting to explore the empirical relations among various information proxies. ${ }^{2}$

Related to this point, our paper underscores the need to better understand the potential trade-offs between information-asymmetry effects and precision effects, for instance, when mandating disclosure. As the debate about Reg FD illustrates, a policy designed to decrease information asymmetry may result, as an unintended consequence, in a decrease in the precision of publicly available information (or vice versa). The presence of both effects in real capital markets could explain why several

2 Along these lines, Verdi (2005) shows that many commonly used information proxies load onto distinct factors in a principal factor analysis; this provides evidence consistent with the notion that information asymmetry and average precision are distinct constructs. 
empirical studies point to an increase in firms' cost of capital subsequent to Reg FD (e.g., Duarte et al., 2006; Gomes et al., 2006), while others find evidence for a decrease (e.g., Dhaliwal et al., 2006). Similarly, the presence of precision and information asymmetry effects can explain the mixed effects of various information attributes on the cost of capital (e.g., Botosan and Plumlee, 2003; Botosan et al., 2004; Francis et al., 2005; Verdi, 2005; Ogneva, 2008).

Finally, our paper contributes more broadly to the growing empirical literature on the link between disclosure and the cost of capital, which is of considerable importance to accounting and finance (see, e.g., surveys by Healy and Palepu, 2001, and Leuz and Wysocki, 2008). Many of the studies in this literature implicitly or explicitly treat information attributes (e.g., information asymmetry, information quality, etc.) as a separate risk factor (e.g., Easley et al., 2002; Francis et al., 2005; Barth et al., 2006; Duarte et al., 2006, Nichols 2006; Chen et al., 2007, Kravet and Shevlin, 2007; Ogneva 2008). In doing so, these studies often refer to Easley and O'Hara (2004) as a conceptual underpinning for their empirical analysis. Our paper shows that the effects in Easley and O'Hara (2004) do not give rise to an information risk factor and that they are not attributable to information asymmetry. This result should be important for the recent debates over whether accruals quality or the probability of informed trade (or PIN), which is a commonly used measure for information asymmetry, are priced in expected returns (e.g., Cohen, 2008; Core et al., 2008; Liu and Wysocki, 2007; Mohanram and Rajgopal, 2008). That said, our analysis does not preclude the existence of information asymmetry effects on firms' cost of capital or the existence of an information risk factor. For instance, such effects could exist in models of imperfect competition. Thus, empirical results that suggest or at least are consistent with a factor interpretation ultimately call for more research on the effects of information 
asymmetry on expected returns and the existence of an information risk factor (see also O'Hara, 2003).

The remainder of this paper is organized as follows. In section 2, we develop the model and derive pricing equations as a function of investors' information structures. In section 3, we analyze specific information structures commonly used in the literature to derive closed-form, pricing equations. Section 4 examines the issue of diversifiabilty. We conclude with a brief summary.

\section{Market prices in a multi-firm economy}

In this section we introduce a classical, one-period capital market setting in which $N$ investors, indexed by $i=1,2, \ldots, N$, allocate their wealth over the shares of $J$ firms and a risk-free asset (e.g., bonds). These settings have a long tradition in finance, and include traditional asset pricing models such as the CAPM (see Fama, 1976), as well as RE-models (which we discuss in more detail below). Let $\tilde{\mathbf{V}}$ denote the $J \times 1$ vector of end-of-period cash flows generated by the firms, and $\tilde{V}_{j}$ its $j$-th element, and $\mathbf{P}$ the $J \times 1$ vector of beginning-of-period market values, or prices, associated with those firms, and $P_{j}$ its $j$-th element. ${ }^{3}$ Each investor has information, represented by $\Phi_{i}$, upon which he forms beliefs about firms' end-of-period cash flows. We allow for the possibility that $\Phi_{i}$ includes both public and private information, as well as information inferred from the vector of market (equilibrium) prices, $\mathbf{P}$. We assume that investors assess the joint distribution of firms' cash flows to have a multivariate normal distribution based on $\Phi_{i}$. Specifically, let $\mathbf{E}_{i}\left[\tilde{\mathbf{V}} \mid \Phi_{i}\right]$ represent investor $i$ 's $J \times 1$ vector of firms' expected values, and $\mathbf{C o v}_{i}$ investor $i$ 's $J \times J$ covariance matrix of

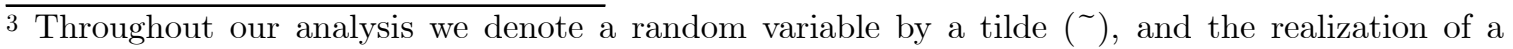
random variable and/or a fixed parameter with no tilde. In addition, we put vectors and matrices in bold. 
firms' end-of-period cash flows, conditional on investor $i$ 's information, $\Phi_{i}$. Below, we discuss in greater detail the specific information that underlies investors' beliefs. For convenience, we represent the precision matrix for investor $i$ 's beliefs by $\Pi_{i}$, where $\Pi_{i}$ is the inverse of covariance matrix investor $i$ associates with firms' end-of-period cash flows: that is, $\boldsymbol{\Pi}_{i}=\mathbf{C o v}_{i}^{-1}$. Finally, let $\Pi_{0}=\sum_{i=1}^{N} \boldsymbol{\Pi}_{i}$ represent the sum of investors' precision matrices.

We assume that each of the $N$ investors has a negative exponential utility function with a risk tolerance of parameter $\tau$, and chooses his portfolio to maximize the expected utility of his end-of-period wealth. Let $\hat{\mathbf{X}}_{i}$ represent the $J \times 1$ vector of investor $i$ 's endowment of firm shares, and $\hat{X}_{i j}$ its $j$-th element, and $\hat{B}_{i}$ his endowment of a risk-free asset (e.g., bonds). Similarly, let $\mathbf{X}_{i}$ represent the $J \times 1$ vector of investor $i$ 's demand for firm shares, and $X_{i j}$ its $j$-th element, and $B_{i}$ the units of the risk-free asset he chooses to hold. We assume that the risk-free asset has an initial price of $\$ 1$, and yields $1+R_{f}$ at the end of the period. Finally, for convenience let $\tilde{\mathbf{X}}_{0}$ represent the $J \times 1$ random vector of total supply of firm shares in the economy, and $\tilde{X}_{0 j}$ its $j$-th element, where the realization $\tilde{X}_{0 j}=X_{0 j}$ has the feature that $X_{0 j}=\sum_{i=1}^{N} X_{i j}=\sum_{i=1}^{N} \hat{X}_{i j}$.

Conditional on a realization of the random supply vector, $\tilde{\mathbf{X}}_{0}=\mathbf{X}_{0}$, we can characterize investor $i$ 's objective function for choosing $\mathbf{X}_{i}$ and $B_{i}$ as follows: ${ }^{4}$

$$
\max _{\mathbf{X}_{i}, B_{i}} E_{i}\left[B_{i}\left(1+R_{f}\right)+\mathbf{X}_{i} \tilde{\mathbf{V}} \mid \Phi_{i}\right]-\frac{1}{2 \tau} \mathbf{X}_{i} \operatorname{Cov}_{i} \mathbf{X}_{i}^{\prime}
$$

subject to $\mathbf{X}_{i} \mathbf{P}^{\prime}+B_{i}=\hat{\mathbf{X}}_{i} \mathbf{P}^{\prime}+\hat{B}_{i}$. Solving the budget constraint for the risk-free asset implies setting $B_{i}=\hat{\mathbf{X}}_{i} \mathbf{P}^{\prime}+\hat{B}_{i}-\mathbf{X}_{i} \mathbf{P}^{\prime}$; substituting this expression into the objective

$\overline{4}$ While we explicitly include the dependence of investor $i$ 's expected cash flow on his information, $\Phi_{i}$, to save space we suppress this dependence in the expressions for the covariance and precision matrices, $\mathbf{C o v}_{i}$ and $\boldsymbol{\Pi}_{i}$, respectively. We also suppress the dependency of price on the information sets of all investors. 
function above implies

$$
\max _{\mathbf{X}_{i}} \mathbf{X}_{i} E_{i}\left[\tilde{\mathbf{V}} \mid \Phi_{i}\right]+\left(\hat{\mathbf{X}}_{i} \mathbf{P}^{\prime}+\hat{B}_{i}-\mathbf{X}_{i} \mathbf{P}^{\prime}\right)\left(1+R_{f}\right)-\frac{1}{2 \tau} \mathbf{X}_{i} \operatorname{Cov}_{i} \mathbf{X}_{i}^{\prime}
$$

Computing the first-order condition for investor $i$ 's demand for firms shares, $\mathbf{X}_{i}$, yields

$$
\mathbf{X}_{i}=\tau \boldsymbol{\Pi}_{i}\left(E_{i}\left[\tilde{\mathbf{V}} \mid \Phi_{i}\right]-\mathbf{P}\left(1+R_{f}\right)\right)
$$

To derive an equilibrium set of prices, we sum the demands of all investors as expressed in eqn. (2), and set them equal to the aggregate supply of shares in each firm. This yields the following expression for the vector of equilibrium prices.

Proposition 1. The vector of market prices depend on investors' information through the following equation:

$$
\mathbf{P}=\frac{\left(\boldsymbol{\Pi}_{0}\right)^{-1} \sum_{i=1}^{N} \boldsymbol{\Pi}_{i} E_{i}\left[\tilde{\mathbf{V}} \mid \Phi_{i}\right]-\left(\frac{1}{N} \boldsymbol{\Pi}_{0}\right)^{-1} \frac{\mathbf{X}_{0}}{N \tau}}{1+R_{f}}
$$

Eqn. (3) illustrates the aggregation property of price. Specifically, the vector of market prices, $\mathbf{P}$, is equal to: the vector of investors' precision-weighted, average assessment of firms' expected end-of-period cash flows, $\left(\boldsymbol{\Pi}_{0}\right)^{-1} \sum_{i=1}^{N} \boldsymbol{\Pi}_{i} E_{i}\left[\tilde{\mathbf{V}} \mid \Phi_{i}\right]$; minus a discount that results from the risk the market associates with holding firms' shares, $\left(\frac{1}{N} \boldsymbol{\Pi}_{0}\right)^{-1} \frac{\mathbf{X}_{0}}{N \tau}$; where both the average assessment of expected values and risk are discounted back to the beginning-of-the-period at the risk-free rate, $1+R_{f}$. Investors' expected values are weighted by their precisions, $\boldsymbol{\Pi}_{i}$, because investors' demands are proportionate to their precisions, ceteris paribus. The risk associated with holding firms' shares, $\left(\frac{1}{N} \boldsymbol{\Pi}_{0}\right)^{-1} \frac{\mathbf{X}_{0}}{N \tau}$, is a function of three elements: 1) the inverse of investors' average precision matrix for the distribution of firms' end-of-period cash flows, $\left(\frac{1}{N} \boldsymbol{\Pi}_{0}\right)^{-1}$, as an expression of the (average) uncertainty associated with holding firms' shares; 2) the total supply of firm shares, $\mathbf{X}_{0}$, that investors are required to 
hold; and 3) the inverse of investors' total tolerance for bearing risk, $N \tau .^{5}$ Taking expected values of eqn. (3) implies that the deviation of prices from the expected end-of-period cash flows discounted at the risk free rate is $\frac{1}{1+R_{f}}\left(\frac{1}{N} \Pi_{0}\right)^{-1} \frac{E\left[\tilde{\mathbf{X}}_{0}\right]}{N \tau} .{ }^{6}$ We define firm $j$ 's cost of capital as the deviation of $P_{j}$ from its ex-ante expected value; that is, the cost of capital is equal to the $j$-th element of $\frac{1}{1+R_{f}}\left(\frac{1}{N} \Pi_{0}\right)^{-1} \frac{E\left[\tilde{\mathbf{x}}_{0}\right]}{N \tau}$. This definition comports with the definition of others (e.g., Easley and O'Hara, 2004).

The salient feature of eqn. (3) is that the economy's information structure affects the cost of capital of firms solely through its effect on the inverse of investors' average precision matrix, $\frac{1}{N} \boldsymbol{\Pi}_{0}$. The precision matrix for investor $i$ is simply the inverse of the covariance matrix he associates with the cash flows of all firms based on his information $\Phi_{i}$. Inverting each investor's covariance matrix, averaging these inverses, and then inverting the average results in a matrix that is analogous to a covariance matrix. Because of the non-linearities involved in matrix inversion, however, this covariance matrix is not the simple average of investors' individual covariance matrices.

Intuitively, a measure of information asymmetry should be related to the extent to which investors' precision matrices differ from each other. But irrespective of how information asymmetry is measured, eqn. (3) shows that the degree of information asymmetry is irrelevant for pricing and the cost of capital, provided that one controls for or holds investors' average precision constant.

Note that the relevant metric for pricing is investors' equilibrium precision matrices; these matrices are conditional upon all available information, including any information investors infer from prices. The notion that investors condition their

5 This last effect is analogous to the one discussed in Merton (1987).

6 While each investor assesses the expected end-of-period cash flows differently, their ex-ante expected values (prior to anyone receiving information) are equal to their prior, which we assume is identical across investors. Similarly, we assume that investors have an identical distribution for the liquidity shock, $\tilde{\mathbf{X}}_{0}$. 
expectations over price, and thereby glean additional information about firms' cash flows through the price aggregation process, is the central tenet of the RE-literature (e.g., Grossman and Stiglitz, 1980; Hellwig, 1980; Diamond and Verrecchia 1981; Admati, 1985; etc.). When this is the case, price is also on the right-hand-side of eqn. (3) as part of $\Phi_{i}$, e.g., it is one of the conditioning variable in the expectation and precision terms. In general, to solve the pricing equation in closed-form, a RE-analysis requires that eqns. (1) and (3) be solved simultaneously, along with the market-clearing condition that investors' demand for firm shares equals the aggregate supply of those shares. ${ }^{7}$ In section 3 , we impose more structure on investors' information so as to solve the pricing equation in closed form. This also enables us to relate parameters in the information structure to the average equilibrium precision matrix, and therefore to the cost of capital.

One application of Proposition 1 that results in a closed-form solution occurs when investors have homogeneous information. We represent homogeneous information by $\Phi_{H}$ : that is, $\Phi_{i}=\Phi_{H}$ for all $i$. Let $\boldsymbol{\Pi}_{H}$ represent investors' homogeneous precision matrix, and $\operatorname{Cov}_{H}$ its inverse: that is, $\boldsymbol{\Pi}_{i}=\boldsymbol{\Pi}_{H}$ and $\operatorname{Cov}_{H}=\boldsymbol{\Pi}_{H}^{-1}$ for all $i$.

Corollary 1. When investors have homogeneous information, market prices are as follows:

$$
\mathbf{P}=\frac{E\left[\tilde{\mathbf{V}} \mid \Phi_{H}\right]-\boldsymbol{\Pi}_{H}^{-1} \frac{\mathbf{x}_{0}}{N \tau}}{1+R_{f}}, \text { or } \mathbf{P}=\frac{E\left[\tilde{\mathbf{V}} \mid \Phi_{H}\right]-\operatorname{Cov}_{H} \frac{\mathbf{x}_{0}}{N \tau}}{1+R_{f}}
$$

When all investors have the same information, their beliefs are homogeneous and hence there is no additional information to glean from price. Thus, Corollary 1 is a closed-form solution for prices. The expression for prices in Corollary 1 is identical

7 If one were to ignore the possibility of investors conditioning their expectations on price by assuming that prices contained too much "noise," then Proposition 1 offers a representation for prices that is analogous to the Lintner's (1969) heterogeneous information version of the CAPM. 
to that in the CAPM (e.g., Sharpe, 1964; Lintner, 1965). ${ }^{8}$ Specifically, the price of each firm is equal to its expected end-of-period cash flow, minus a discount for the risk associated with holding that firm's shares. ${ }^{9}$

\section{Market prices with heterogeneous information}

In this section we extend our analysis to heterogeneous information across investors in conjunction with investors conditioning their expectations over price to study two information structures in the RE-literature: diverse information, as in Grossman (1976) and Kim and Verrecchia (1991), and superior/inferior information, as in Grossman and Stiglitz (1980), Easley and O'Hara (2004), and Hughes, et al. (2007). To be able to solve for prices in closed-form, we assume the following information structure. First, investors have a common prior over the distribution of the vector of end-ofperiod cash flows, $\tilde{\mathbf{V}}$. Let $\mathbf{m}$ represent the $J \times 1$ vector of common prior beliefs about the expected value of $\tilde{\mathbf{V}}$, and $m_{j}$ its $j$-th element, and $\boldsymbol{\Psi}$ the $J \times J$ common prior precision matrix of $\tilde{\mathbf{V}}$. Note that in this formulation we allow for the cash flows to be correlated across firms. Each firm has associated with it a public announcement. Let $\tilde{\mathbf{y}}$ represent the $J \times 1$ vector of announcements, and $\tilde{y}_{j}$ its $j$-th element. We assume that announcements have a normal distribution, where $\boldsymbol{\eta}$ represents the $J \times J$ precision matrix of $\tilde{\mathbf{y}} .{ }^{10}$ We assume that announcements are unbiased, but impose no structure on $\boldsymbol{\eta}$. For example, neither the variances across announcements, nor 8 The CAPM assumes that the supply vector, $\mathbf{X}_{0}$, is deterministic, and expresses investors' demands in terms of the percentage of firms' shares held, so that the total supply sums to 1 .

9 For example, the discount for holding firm $j$ 's shares is proportional to $\sum_{k=1}^{N} \operatorname{Cov}\left[\tilde{V}_{j}, \tilde{V}_{k} \mid \Phi_{H}\right]$, where $\sum_{k=1}^{N} \operatorname{Cov}\left[\tilde{V}_{j}, \tilde{V}_{k} \mid \Phi_{H}\right]$ represents firm $j$ 's contribution to the aggregate uncertainty investors associate with the cash flows of all firms, $\operatorname{Var}\left[\sum_{k=1}^{N} \tilde{V}_{k} \mid \Phi_{H}\right]$.

$10 \mathrm{It}$ is straightforward to extend the model to allow for a vector of announcements about each firm, or for each investor to observe a vector of private information about each firm. 
the covariances across pairs of announcements, need be identical. Each investor has private information about each firm. Let $\tilde{\mathbf{z}}_{i}$ represent the $J \times 1$ vector of information available to investor $i$, and $\tilde{z}_{i j}$ its $j$-th element. As with public announcements, we assume that private information is unbiased and has a normal distribution. Let $\mathbf{S}_{i}$ represent investor $i$ 's $J \times J$ precision matrix for $\tilde{\mathbf{z}}_{i}$ conditional on $\tilde{\mathbf{V}}=\mathbf{V}$. As is standard practice in the literature, we assume that $\tilde{\mathbf{y}}$ and $\tilde{\mathbf{z}}_{i}$ are independent conditional on $\tilde{\mathbf{V}}=\mathbf{V}$.

We impose no structure on the precision matrix of private information $\mathbf{S}_{i}$ : for each investor the variance in private information can be different across firms, and $\mathbf{S}_{i}$ can differ across investors. In particular, this implies that investors need not receive private information of equal quality. For example, some investors might not be endowed with any private information, in which case $\mathbf{S}_{i}$ is a $J \times J$ matrix of 0's. In fact, it is precisely this feature - how the quality of information differs across investors - that we are interested in examining. As discussed above, information (both public and private) is useful in investors' demands for all firms. That is, public information (say, earnings) for firm $j$ will, in general, be useful for both revising the assessment of expected end-of-period cash flow for firm $j$ and for other firms whose cash flows covary with firm $j$.

As is standard in the RE-literature, we prevent prices from being fully revealing by assuming that the aggregate supply of firm shares is uncertain. Specifically, we assume that the aggregate supply vector, $\tilde{\mathbf{X}}_{0}$, has a normal distribution. This implies that prices, as information sources, incorporate noise in the form of an aggregate supply shock. As is also the convention in the RE-literature, we couch our analysis in the context of the distribution of the supply shock per-capita: that is, in terms of $\tilde{\mathbf{x}}_{0}$, where $\tilde{\mathbf{x}}_{0}$ represents the $J \times 1$ vector of per-capita supply shocks, and $\tilde{x}_{0 j}=\frac{\tilde{X}_{0 j}}{N}$ 
represents its $j$-th element. Note that the vector of per-capita supply shocks, $\tilde{\mathbf{x}}_{0}$, also has a normal distribution. Let $\overline{\mathbf{x}}_{0}$ represent the $J \times 1$ vector of expected values of $\tilde{\mathbf{x}}_{0}$, where $\bar{x}_{0 j}$ represents its $j$-th element, and $\mathbf{W}$ the $J \times J$ precision matrix of $\tilde{\mathbf{x}}_{0}$. We assume that the distribution of $\tilde{\mathbf{x}}_{0}$ is independent of all other variables.

\subsection{Diverse information}

In Kim and Verrecchia (1991), the distribution of the private information, $\tilde{\mathbf{z}}_{i}$, conditional on $\tilde{\mathbf{V}}=\mathbf{V}$, is independent across investors. In other words, each investor observes a vector of information whose error terms can be correlated across firms, but uncorrelated across investors. To start, as described above, each investor receives a vector of private information, $\tilde{\mathbf{z}}_{i}$, where each vector has associated with it a conditional precision matrix $\mathbf{S}_{i}$. As is standard in solving a RE-equilibrium, we assume investors conjecture that the vector of prices has the following linear functional form: $\tilde{\mathbf{P}}=\mathbf{a}+\mathbf{b} \tilde{\mathbf{V}}+\mathbf{c} \tilde{\mathbf{y}}-\mathbf{d} \tilde{\mathbf{x}}_{0}+\mathbf{e} \overline{\mathbf{x}}_{0}$. That is, investors conjecture that the price vector is a linear function of vectors of true cash flows, $\tilde{\mathbf{V}}$, public announcements, $\tilde{\mathbf{y}}$, and supply shocks, $\tilde{\mathbf{x}}_{0}$ and $\overline{\mathbf{x}}_{0}$, where $\mathbf{a}$ is a $J \times 1$ vector of intercepts, and $\mathbf{b}, \mathbf{c}, \mathbf{d}$, and $\mathbf{e}$ are $J \times J$ matrices of coefficients. Note that in this formulation the price of each firm is allowed to be a function of the information about all other firms in the market. For this same reason, the price of one firm also conveys information about other firms. In particular, we describe the additional information investors infer by conditioning their expectations over price as the "orthogonal" information in price. We represent the orthogonal information in price with a variable $\tilde{\mathbf{u}}$, where $\tilde{\mathbf{u}}$ is defined by

$$
\tilde{\mathbf{u}}=\mathbf{b}^{-1}\left(\tilde{\mathbf{P}}-\mathbf{a}-\mathbf{c} \tilde{\mathbf{y}}+(\mathbf{d}-\mathbf{e}) \overline{\mathbf{x}}_{0}\right)=\tilde{\mathbf{V}}-\mathbf{b}^{-1} \mathbf{d}\left(\tilde{\mathbf{x}}_{0}-\overline{\mathbf{x}}_{0}\right) .
$$

Note that $\mathbf{b}^{-1} \mathbf{d}$ is a $J \times J$ matrix. Conditional on $\tilde{\mathbf{V}}=\mathbf{V}$, the covariance matrix for orthogonal information is $\mathbf{b}^{-1} \mathbf{d} \cdot \mathbf{W}^{-1} \cdot\left(\mathbf{b}^{-1} \mathbf{d}\right)^{\prime}$. Finally, let $\boldsymbol{\theta}$ represent 
the precision matrix for orthogonal information conditional on $\tilde{\mathbf{V}}=\mathbf{V}$ : that is, $\boldsymbol{\theta}=\left(\mathbf{b}^{-1} \mathbf{d} \cdot \mathbf{W}^{-1} \cdot\left(\mathbf{b}^{-1} \mathbf{d}\right)^{\prime}\right)^{-1}$. Note that even though investors have diverse private information, the precision of the orthogonal information (i.e., the incremental information investors glean from price) is the same across investors.

In the context of this information structure, investor $i$ 's expected value of firms' cash flows becomes $E_{i}[\tilde{\mathbf{V}}]=\boldsymbol{\Pi}_{i}^{-1}\left(\boldsymbol{\Psi} \mathbf{m}+\boldsymbol{\eta} \mathbf{y}+\mathbf{S}_{i} \mathbf{z}_{i}+\boldsymbol{\theta} \mathbf{u}\right)$, where $\boldsymbol{\Pi}_{i}=\boldsymbol{\Psi}+\boldsymbol{\eta}+\mathbf{S}_{i}+\boldsymbol{\theta}$ is the total equilibrium precision matrix of investor $i$. The total equilibrium precision matrix consists of an investor's prior, $\boldsymbol{\Psi}$, the public announcements, $\boldsymbol{\eta}$, his private information, $\mathbf{S}_{i}$, and the orthogonal information from price, $\boldsymbol{\theta}$. The key insight here is that when investor $i$ conditions his expectations on his priors, public information, private information, and price, the total precision of his information is simply the sum of the precision matrices of his priors, the public announcements, his private information, and the precision matrix of the orthogonalized price vector.

Let $\operatorname{Avg}[\cdot]=\frac{1}{N} \sum_{i=1}^{N}[\cdot]$ represent an averaging function across investors: for example, recalling the definition of $\boldsymbol{\Pi}_{0}$ in Section 2, this implies that $\operatorname{Avg}\left[\boldsymbol{\Pi}_{i}\right]=\frac{1}{N} \boldsymbol{\Pi}_{0}$. Eqn. (3) identifies the average precision of information across investors as the key variable in determining the discount in prices; here, $\operatorname{Avg}\left[\boldsymbol{\Pi}_{i}\right]=\boldsymbol{\Psi}+\boldsymbol{\eta}+\operatorname{Avg}\left[\mathbf{S}_{i}\right]+\boldsymbol{\theta}$. The only remaining task is to solve for $\boldsymbol{\theta}$, the precision matrix of the information conveyed by price. To do this, we solve for the parameters $\mathbf{b}$ and $\mathbf{d}$ in the conjectured functional form for price. Substituting the expected cash flows and precisions into the pricing eqn. (3) and summing across all investors gives us an equation for prices. We equate the coefficients from this equation with those from the conjectured functional form to solve for the parameters $\mathbf{b}$ and $\mathbf{d}$.

Recall that we define cost of capital as the deviation of prices from the expected end-of-period cash flows 
Proposition 2. Information affects cost of capital through the average precision of investors' information,

$$
E[\tilde{\mathbf{V}}]-E[\tilde{\mathbf{P}}]=\frac{1}{1+R_{f}} \operatorname{Avg}\left[\boldsymbol{\Pi}_{i}\right]^{-1} \frac{1}{\tau} E\left[\tilde{\mathbf{x}}_{0}\right],
$$

where

$$
\operatorname{Avg}\left[\boldsymbol{\Pi}_{i}\right]=\boldsymbol{\Psi}+\boldsymbol{\eta}+\operatorname{Avg}\left[\mathbf{S}_{i}\right]+\boldsymbol{\theta},
$$

and the precision of the information conveyed by price is

$$
\boldsymbol{\theta}=\tau^{2}\left(\operatorname{Avg}\left[\mathbf{S}_{i}\right]\right) \cdot \mathbf{W} \cdot\left(\operatorname{Avg}\left[\mathbf{S}_{i}\right]\right)^{\prime} .
$$

The contribution of Proposition 2 is that now we can solve in closed form the discount in price relative to the expected end-of-period cash flow that we first characterized in Proposition 1. Specifically, Proposition 2 confirms that the discount in price is governed by the average precision of information across investors. Moreover, note that increasing the precision of private information for any subgroup of investors (including groups who already possess above average precision) lowers cost of capital because it affects the average total precision in two mutually reinforcing ways: a direct effect and an indirect effect through $\boldsymbol{\theta}$, the precision of the information conveyed by price. When cash flows, information, and liquidity shocks are all independently distributed across firms, each firm is priced independently, and Proposition 2 reduces to the same result found in Kim and Verrecchia's (1991) single-firm analysis.

\subsection{Superior information}

In this section, we turn to the issue of information asymmetry and examine information structures in which all investors are classified into two groups: those who get private information and those who do not. The less-informed group consists of $N_{1}$ 
investors who only observe public information signals and price. We assume there are $Q_{1}$ public signals $\tilde{\mathbf{y}}_{h}, h=1, \ldots, Q_{1}$, where each public signal is a $J \times 1$ vector of information announcements about the firms' cash flows, $\tilde{\mathbf{y}}_{h}=\tilde{\mathbf{V}}+\tilde{\mathbf{e}}_{h}$. For each public signal, the vector of error terms $\tilde{\mathbf{e}}_{h}$ has expected value of zero and a $J \times J$ precision matrix denoted $\boldsymbol{\eta}$. The individual precisions can differ across firms and the covariances of the error terms can be non-zero. The more informed group consists of $N_{2}=N-N_{1}$ investors who observe the $Q_{1}$ vectors of public signals and also $Q_{2}$ vectors of private signals, $\tilde{\mathbf{z}}_{k}=\tilde{\mathbf{V}}+\tilde{\boldsymbol{\zeta}}_{k}, k=1, \ldots, Q_{2}$. In contrast to the prior section, all investors in the more informed group observe exactly the same realization of private signals. As with the public signals, we allow the precisions of the signals to differ across firms and the covariances in their error terms to be non-zero. Therefore a public or private signal about one firm can convey information about the future cash flow of other firms. We assume that each of the vectors of public signals $\tilde{\mathbf{y}}_{h}$ and each of the vectors of private signals $\tilde{\mathbf{z}}_{k}$ are conditionally independent of each other. Also as before, each investor has a common prior on the distribution of the end-of-period cash flow, $\tilde{\mathbf{V}}$; specifically, investors believe that $\tilde{\mathbf{V}}$ has a normal distribution with mean $\mathbf{m}$ and precision $\Psi$.

The more informed group observes all public and private information available in the economy. Hence, the more informed group cannot learn any additional information from price. In effect, for the more informed group, price is a redundant source of information. Let $\tilde{\mathbf{Y}}=\sum_{h=1}^{Q_{1}} \tilde{\mathbf{y}}_{h}$ and $\tilde{\mathbf{Z}}=\sum_{k=1}^{Q_{2}} \tilde{\mathbf{z}}_{k}$ represent summary statistics for the vectors of public and private signals, respectively. Conditional upon the realization of public and private information (i.e., conditional on $\tilde{\mathbf{Y}}=\mathbf{Y}$ and $\tilde{\mathbf{Z}}=\mathbf{Z}$ ), the conditional expectation of end-of-period cash flow of more informed investors is

$$
E\left[\tilde{\mathbf{V}} \mid \mathbf{y}_{1}, \ldots, \mathbf{y}_{Q_{1}}, \mathbf{z}_{1}, \ldots, \mathbf{z}_{Q_{2}}\right]=\left[\mathbf{\Psi}+Q_{1} \boldsymbol{\eta}+Q_{2} \mathbf{S}\right]^{-1}[\mathbf{\Psi} \mathbf{m}+\boldsymbol{\eta} \mathbf{Y}+\mathbf{S Z}]
$$


where the total precision matrix of their information is $\boldsymbol{\Pi}_{2}=\boldsymbol{\Psi}+Q_{1} \boldsymbol{\eta}+Q_{2} \mathbf{S}$. Note that the total precision is increasing in the prior precision, $\boldsymbol{\Psi}$, the precision matrices per public and private signal, $\boldsymbol{\eta}$ and $\mathbf{S}$, and the number of each type of signal, $Q_{1}$ and $Q_{2}$.

Members of the less informed group base their investment decisions on the $Q_{1}$ public signals and price. As before, to ensure that price is not fully revealing, we assume the shock to the aggregate supply creates noise. Specifically, we assume that the aggregate per-capita supply for the firms can be represented by the $J \times 1$ vector $\tilde{\mathbf{x}}_{0}$. Let $\overline{\mathbf{x}}_{0}$ represent the $J \times 1$ vector of expected values of $\tilde{\mathbf{x}}_{0}$, where $\bar{x}_{0 j}$ represents its $j$-th element, and $\mathbf{W}$ the $J \times J$ precision matrix of $\tilde{\mathbf{x}}_{0}$. We assume that the distribution of $\tilde{\mathbf{x}}_{0}$ is independent of all other variables.

As in the previous subsection, a solution to a RE-equilibrium starts by requiring that less informed investors conjecture that price is in the form $\tilde{\mathbf{P}}=\mathbf{a}+\mathbf{b} \tilde{\mathbf{Z}}+\mathbf{c} \tilde{\mathbf{Y}}-$ $\mathbf{d} \tilde{\mathbf{x}}_{0}+\mathbf{e} \overline{\mathbf{x}}_{0}$. Here we represent the orthogonal information in price with a variable $\tilde{\mathbf{u}}$, where $\tilde{\mathbf{u}}$ is defined by

$\tilde{\mathbf{u}}=\frac{\mathbf{b}^{-1}}{Q_{2}}\left[\tilde{\mathbf{P}}-\mathbf{a}-\mathbf{c} \tilde{\mathbf{Y}}+\overline{\mathbf{x}}_{0}(\mathbf{d}-\mathbf{e})\right]=\frac{\tilde{\mathbf{Z}}}{Q_{2}}-\frac{\mathbf{b}^{-1} \mathbf{d}}{Q_{2}}\left(\tilde{\mathbf{x}}_{0}-\overline{\mathbf{x}}_{0}\right)=\tilde{\mathbf{V}}+\frac{\sum_{k=1}^{Q_{2}} \tilde{\boldsymbol{\zeta}}_{k}}{Q_{2}}-\frac{\mathbf{b}^{-1} \mathbf{d}}{Q_{2}}\left(\tilde{\mathbf{x}}_{0}-\overline{\mathbf{x}}_{0}\right)$.

As before, the orthogonal information in price represents the incremental information less informed investors infer by conditioning their expectations on price. In our multifirm setting, the price of one firm can convey information not only about that firm's cash flow, but also about the cash flows of other firms. The presence of an aggregate supply shock makes orthogonal information in price a noisy measure of the private information available to more informed investors, $\tilde{\mathbf{Z}}$.

Let $\boldsymbol{\theta}$ denote the precision matrix that characterizes the error in $\tilde{\mathbf{u}}$ as a measure of $\tilde{\mathbf{V}}$. As a consequence of conditioning their expectations on price, the total precision 
of investors in the less informed group is $\Pi_{1}=\boldsymbol{\Psi}+Q_{1} \boldsymbol{\eta}+\boldsymbol{\theta}$. As above, $\boldsymbol{\Psi}$ represents investors' common prior precision matrix; similarly, $Q_{1} \boldsymbol{\eta}$ is the precision matrix of the public signals. While less informed investors have no private information, they glean the private information of more informed investors (with noise) when they condition their expectations on price. Here, $\boldsymbol{\theta}$ represents the precision matrix of the additional information less informed investors infer from price.

To solve the pricing equation in closed form and be able to calculate the average equilibrium precision, we must calculate the precision of the information obtained from price. This then allows the following characterization of the cost of capital.

Proposition 3. When cash flows are cross-sectionally correlated, information affects cost of capital through the average precision of investors' information,

$$
E[\tilde{\mathbf{V}}]-E[\tilde{\mathbf{P}}]=\frac{1}{1+R_{f}} \operatorname{Avg}\left[\mathbf{\Pi}_{i}\right]^{-1} \frac{1}{\tau} E\left[\tilde{\mathbf{x}}_{0}\right]
$$

where

$$
A v g\left[\boldsymbol{\Pi}_{i}\right]=\frac{N_{1}}{N}\left(\Psi+Q_{1} \boldsymbol{\eta}+\boldsymbol{\theta}\right)+\frac{N_{2}}{N}\left(\Psi+Q_{1} \boldsymbol{\eta}+Q_{2} \mathbf{S}\right),
$$

and the precision of information that less informed investors infer from price is

$$
\boldsymbol{\theta}=\left[\frac{1}{Q_{2}} \mathbf{S}^{-1}-\left(\frac{1}{\tau} \frac{N}{N_{2}} \frac{1}{Q_{2}}\right)^{2} \mathbf{S}^{-1} \cdot \mathbf{W}^{-1} \cdot\left(\mathbf{S}^{-1}\right)^{\prime}\right]^{-1}
$$

The first term in eqn. (4) is the precision of less informed investors, weighted by their relative population in the economy, $\frac{N_{1}}{N}$, and the second term is the precision of more informed investors, weighted by their relative population, $\frac{N_{2}}{N}$.

The significance of Proposition 3 is that it shows how our average precision result extends to a superior-information structure with multiple firms. Average precision governs the discount in price associated with the market holding firms' shares. Thus, as the expression for average precision in eqn. (4) goes up or down, cost of capital correspondingly decreases or increases. 
To help analyze the determinants of average precision and to compare our results to those in the literature, we consider the special case where all firms' cash flows, information signals, and liquidity shocks are distributed independently across firms. In this case, the average precision matrix is diagonal, and all firms are priced independently. ${ }^{11}$ Therefore, our analysis becomes comparable to work that analyzes information issues in a single-firm economy. In particular, we compare our results to those in Easley and O'Hara (2004) (henceforth EOH), who also analyze the implications for the cost of capital when some investors possess superior (private) information, but emphasize the role of private information and information differences across investors for their results. Thus, in the remainder of the section, we discusses the relation between average information precision and information asymmetry.

To facilitate a comparison with $\mathrm{EOH}$, we further specialize our results so that the public and private signals have identical information properties. Let the precision of the error terms in each of the private and public signals be denoted $s$ (we drop the bold notation to indicate we are now dealing with scalars). Moreover, to keep the notation from getting too cumbersome, we do not include a subscript $j$ to distinguish among firms. Finally, we define the following terms to replicate notation used in EOH. Let $Q$ be the total number of information signals observed by more informed investors, where $Q \equiv Q_{1}+Q_{2}$, and $\alpha$ be the percentage of all signals that are private (i.e., $\left.\alpha=\frac{Q_{2}}{Q_{1}+Q_{2}}\right)$. The fraction of investors in the informed group is $\mu$, where $\mu=\frac{N_{2}}{N_{1}+N_{2}}$.

Under these additional assumptions, the average precision of investors' information becomes:

$$
\operatorname{Avg}\left[\Pi_{i}\right]=\frac{N_{1}}{N}\left(\Psi+Q_{1} s+\theta\right)+\frac{N_{2}}{N}\left(\Psi+\left(Q_{1}+Q_{2}\right) s\right)
$$

11In the next section we consider the affect of non-zero correlations across firms and non-zero offdiagonal elements of the average precision matrix. 


$$
=\Psi+(1-\alpha) Q s+\mu \alpha Q s+(1-\mu) \theta
$$

where the precision of the information conveyed by price reduces to

$$
\theta=\left(\frac{1}{Q_{2} s}+\left(\frac{1}{\frac{N_{2}}{N} \tau s}\right)^{2} \frac{1}{Q_{2}^{2} w}\right)^{-1}
$$

Eqns. (5a) and (5b) are identical to the cost of capital equations in EOH. The closed-form solution for the cost of capital shows that it depends on the average precision of the two groups. The weights are the percentage of investors in each group: $\mu$ for the informed group, and $1-\mu$ for the less informed group. The relevant metric for pricing is investors' total average equilibrium precision, which includes the inference the less informed group makes from price, and not the differences in investors' precision matrices.

Next we turn to comparative statics on the cost of capital.

Corollary 2. The cost of capital is decreasing in the following:

a) $1-\alpha$, the percentage of signals that are public (holding constant the total number of signals);

b) $\mu$, the percentage of investors that are informed;

c) $Q_{1} s$, the total precision of the public signals available to both groups (holding $Q_{2}$ constant);

d) $Q_{2}$ s, the total precision of the private signals available only to the more informed group (holding $Q_{1}$ constant).

Each of these parameter changes results in an increase in the average equilibrium precision of investors in the economy; hence, cost of capital decreases. In cases (a), (c), and (d), the precision of information for at least one group increases, and no group has their precision decrease. In case (b), investors are transferred from the lower precision group to the higher precision group. This obviously increases the 
precision of their information, leaves unchanged the precision of the investors already in the informed group, and increases the precision of the investors remaining in the less informed group. The latter result occurs because price becomes more informative.

EOH derive results analogous to the first two results in Corollary 2, but interpret the cause as arising from changes in the composition of private and public information and hence the asymmetry of signals across investors. ${ }^{12}$ To illustrate why these interpretations are different, we offer a measure of information asymmetry and then revisit our comparative statics in light of this measure. Because there are only two groups, and each investor within each group observes identical information-signal realizations, informed asymmetry could be measured simply as the difference between the two groups' precisions of information, $\Pi_{2}-\Pi_{1}$. A shortcoming with this approach, however, is that it fails to reflect changes that occur to the composition of the two groups, such as in result (b) above. Thus, we measure information asymmetry as the variance of the precisions across the investors in the economy. Specifically, let $I A(\cdot)$ be a computation of the variance in investors' precisions; when there are only two groups, it can be shown that $I A(\cdot)$ reduces to a simple form:

$$
I A(\Pi)=\frac{N_{1}}{N} \frac{N_{2}}{N}\left(\Pi_{2}-\Pi_{1}\right)^{2}=\mu(1-\mu)(\alpha Q s-\theta)^{2} .
$$

In short, our measure of information asymmetry is the product of the proportions of investors in each group and the square of the difference in their precisions.

Employing this measure of information asymmetry, it is a straightforward exercise to show that as the percentage of signals that are public increases as in case (a) above, information asymmetry and average precision move in concert. For the remaining

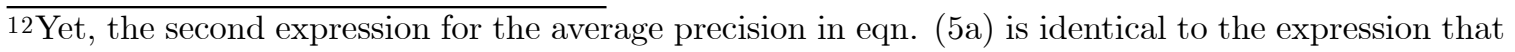
appears in EOH's pricing equation in their Proposition 2. EOH choose a parameterization where the total information content of the signals is held constant but the composition changes. Despite this parameterization, the average equilibrium precision changes and this is what drives the results. 
three results in Corollary 2, however, information asymmetry and average precision do not move in concert, making it easier to distinguish their effects. In case (b), information asymmetry is a non-monotonic function of $\mu$, the percentage of investors in the informed group. Information asymmetry is zero at the two extremes, when all investors are in either the informed group or the uninformed group. In case (d), providing more information to the informed group obviously increases their precision. This also indirectly increases the precision of the information of the uninformed group because prices are more informative. Despite the fact that prices transmit information with noise, the precision of information for the less informed group does not increase as quickly as the precision of information for the more informed group. As a result, information asymmetry between the two groups increases.

These cases illustrate that it is not information asymmetry, but the average precision that determines the effect on the cost of capital. Once one controls for average precision, information asymmetry has no effect on the cost of capital. There are some circumstances where reducing information asymmetry can appear to reduce cost of capital, e.g., case (a). Note, however, that the reason why providing less informed investors access to information previously available only to more informed investors reduces cost of capital is because the average precision of investors' information increases, not because information asymmetry decreases. In contrast, an attempt to reduce information asymmetry by limiting informed investors' access to more information increases cost of capital because investors' average precision is lower. Therefore, attempts at "level the playing field" by providing all investors with the same information have an ambiguous effect on the cost of capital. If the playing field is "leveled" by increasing the information available to the less informed group, cost of capital goes down. If the playing field is leveled by restricting the ability of informed investors to 
acquire additional private signals, then cost of capital will rise. In summary, the communication of more information to more investors, not the reduction of information asymmetry per se, lowers cost of capital.

\section{Disclosure and diversification}

Section 3 establishes that the discount the market associates with holding firms' shares relies on investors' average precision matrix for the distribution of firms' endof-period cash flows. In this section we address whether an individual firm can affect its discount by disclosing additional information about its cash flow. Recall that we define cost of capital as $\frac{1}{1+R_{f}}\left(\frac{1}{N} \boldsymbol{\Pi}_{0}\right)^{-1} \frac{E\left[\tilde{\mathbf{x}}_{0}\right]}{N \tau}$. It is straightforward to show that when there are only a finite number of investors in the economy (i.e., $N$ is finite), additional disclosure by firm $j$ will reduce its discount by increasing the average precision in investors' information, $\frac{1}{N} \boldsymbol{\Pi}_{0}$. Such an effect will occur even if firms' cash flows are viewed to be independently distributed. Nonetheless, it could be argued that the finite- $N$ case is uninteresting in the context of the CAPM in that it fails to capture the effect of diversification. Thus, in this section we study the effect of disclosure by firm $j$ on its discount in the presence of diversification.

Diversification is achieved typically by appealing to the notion of a large economy. So as to avoid cases as uninteresting as the finite- $N$ case, however, some consideration should be given to how one defines a "large economy." For example, if by "large economy" one means that the number of investors in the economy gets large (i.e., $N$ gets large), while all other features of the economy remain finite, then diversification alone eliminates any discount because $\frac{E\left[\tilde{\mathbf{x}}_{0}\right]}{N \tau}$ approaches 0 . Therefore, to be economically interesting, we define a "large economy" as one in which both the number of investors, $N$, and the number of firms, $J$, become large (see also Hughes et al., 2007; Lambert 
et al., 2007). That is, each firm remains finite, but the number of firms increases.

To illustrate how an individual firm can affect its discount, we consider the case where all investors have the same precision of information, but the information itself is diverse: that is, we assume $\Pi_{i}=\Pi_{\Omega}$ and $\mathbf{C o v}_{i}=\operatorname{Cov}_{\Omega}$ for all $i$. Here, it is straightforward to show that firms' cost of capital is proportional to $\operatorname{Cov}_{\Omega} \frac{E\left[\tilde{\mathbf{X}}_{0}\right]}{N \tau}$. This expression, in turn, implies that firm $j$ 's cost of capital is proportional to

$$
\frac{1}{N \tau} \sum_{k=1}^{J} \operatorname{Cov}_{j, k} E\left[\tilde{X}_{0 k}\right]=\frac{1}{N \tau}\left(\operatorname{Cov}_{j, j} E\left[\tilde{X}_{0 j}\right]+\sum_{k \neq j}^{J} \operatorname{Cov}_{j, k} E\left[\tilde{X}_{0 k}\right]\right),
$$

where $\operatorname{Cov}_{j, k}$ represents the $j$-th, $k$-th element of the matrix $\operatorname{Cov}_{\Omega}$. The right-handside of eqn. (6) is analogous to the discount for risk in the traditional CAPM, except in our analysis the covariances are multiplied by the expected supply of firms' shares; in the CAPM, the expected supply of firms' shares (in percentage terms) is 1 . If the off-diagonal elements of the covariance matrix $\mathbf{C o v}_{\Omega}$ are zero, the left-hand-side of eqn. (6) reduces to $\frac{1}{N \tau} \operatorname{Cov}_{j, j} E\left[\tilde{X}_{0 j}\right]$. This expression approaches 0 as $N$ gets large. This is consistent with the concept of "diversifiable risk." Thus, here the average precision of investors' information is irrelevant; as such, any disclosure by firm $j$ intended to affect the average precision is also irrelevant. ${ }^{13}$ If the off-diagonal elements are non-zero, however, $\sum_{k \neq j}^{J} \operatorname{Cov}_{j, k} E\left[\tilde{X}_{0 k}\right]$ will grow as the number of firms in the economy, $J$, grows; this implies that $\frac{1}{N \tau} \sum_{k \neq j}^{J} \operatorname{Cov}_{j, k} E\left[\tilde{X}_{0 k}\right]$ will not approach 0 . In short, for firm $j$ 's cost of capital to remain positive in a large economy (as we have defined it), firms' cash flows must covary.

When firms' cash flows covary and the error in firm $j$ 's disclosure is independent of all other variables, the following result holds.

13This implies that the information effects in EOH are diversifiable. Hughes, et al. (2007) raise a similar point about EOH. However, like EOH, they cast the effects in their model as being driven by information asymmetry, when in fact they are precision effects.Thus, our results on the role of information precision apply equally to Hughes, et al. (2007). 
Proposition 4. When all investors have the same precision of information, but the information itself is diverse, and the error in firm j's disclosure is independent of all other variables, firm j's cost of capital moves closer to the risk free rate as the precision in its disclosure about its cash flow increases.

Proposition 4 demonstrates that disclosure by a firm attenuates the discount for the risk the market associates with holding shares of that firm, even when the quality of its disclosure is idiosyncratic (i.e., independent of all other variables). This result extends the estimation risk literature (e.g., Brown, 1979; Barry and Brown, 1984 and 1985), which analyzes information structures that are identical across investors based on the historical time-series of returns from a stationary process, but has difficulty in signing the effects of information differences across firms. It also extends recent work on the role of accounting information for firms' estimation risk by Lambert, et al. (2007), which is confined to a CAPM setting with homogeneous information among investors.

Similarly, in the superior information scenario, if the off-diagonal terms of the investors' covariance matrices are zero, this will also be true in their precision matrices, and in the average precision matrix. As a result, the cost of capital for firm $j$ will be will equal to the average precision for that firm times the expected supply of firm $j$ shares per-capita. Because the expected number of shares for firm $j$ remains constant as the economy as a whole grows, the expected supply per-capita goes to zero. Since the average precision will be bounded, this implies the cost of capital will approach zero. Again, this shows that it is the off-diagonal terms in investors' covariance and precision matrices that are critical in determining the firm's cost of capital. 


\section{Conclusion}

This paper examines how the distribution of information across investors affects firms' cost of capital in a rational expectations $(\mathrm{RE})$ economy with perfect competition. In contrast to models commonly found in the RE-literature, we consider an economy with multiple firms whose cash flows are correlated. We find that when investors have different information, prices are a function of two features of the economy's information structure: 1) the precision-weighted average of individual investors' vector of expected end-of-period cash flows; and 2) the average of investors' precision matrices of the distribution of firms' end-of-period cash flows.

The latter feature determines the discount in prices relative to firms' expected cash flows. That is, the average of investors' precisions (including any inferences they glean from price) is a primary determinant of cost of capital. No other attribute of investors' information is relevant to firms' cost of capital. In particular, once one controls for average precision, the extent of information asymmetry in the economy (which we measure by the difference in individual investors' precision matrices relative to the average precision matrix) has no effect on the cost of capital. Reducing information asymmetry can appear to lower cost of capital in some situations by providing less informed investors access to information previously available only to better informed investors. In this case, however, the cost of capital decreases because the average precision of investors' information increases, not because information asymmetry decreases. In other words, the communication of more information to more investors, not the reduction of information asymmetry, lowers cost of capital. Conversely, attempts at "level the playing field" by restricting the ability of informed investors to acquire additional information will increase firms' cost of capital. This 
contrasts with the leveling effect on the cost of capital by increasing the information available to the less-informed group described earlier.

Why are prices not lower for firms where less informed investors face greater information disadvantages? We believe the critical feature of the model that drives this result is that the markets are characterized by perfect competition across investors. Perfect competition is a standard feature of many asset pricing models, including those commonly found in the RE-literature. Under perfect competition, each investor's demand for the shares of firm is decreasing in his assessed degree of uncertainty (increasing in his assessed precision) about that firm's future cash flow. While less informed investors demand fewer shares when they perceive uncertainty to be high, more informed investors demand more shares. Because demand is linear in each investor's precision, the relevant metric when investors' demands are aggregated to clear the market is the average precision.

Moreover, the assessed uncertainty about a firm's cash flow (or the discount for risk) is not greater when the investor perceives that other investors possess more precise information. In fact, an investor's degree of uncertainty decreases when other investors acquire more information, because this information becomes (partially) communicated through price when investors condition their expectations over price in determining their demand. As each investor determines his demand for firm shares based on a conjecture that his demand cannot affect price, more informed investors do not reduce their demand strategically for fear of revealing their information to others. More importantly, no trading takes place until an equilibrium price is set. Less informed investors can transact any quantity at this market clearing price. In addition, they are able to use price as a conditioning variable in setting their expectations and assessing risk when they submit their demand order. Thus, with perfect 
competition, information asymmetry does not result in adverse selection and there is no compensation for being less informed.

The fact that the average of investors' precisions is a primary determinant of cost of capital should not be interpreted as suggesting that information asymmetry's role in welfare is benign. It should be clear that when better informed investors participate in the economy, they will achieve a higher expected utility than less well informed investors (ceteris paribus ). But cost of capital and welfare are distinct phenomena; as such they need not comport with one another (see, e.g., Gao, 2008).

In addition, the fact that the average of investors' precisions is a primary determinant of cost of capital in a setting of perfect competition should not be interpreted as suggesting that information asymmetry cannot play a role in other economic settings. In particular, a natural avenue for future research is to examine the role of information asymmetry in imperfect competition settings. For example, Copeland and Galai (1983) and Glosten and Milgrom (1985) point out that asymmetric information can exacerbate adverse selection, thereby leading to higher bid-ask spreads. ${ }^{14}$ Closer in spirit to our analysis, Diamond and Verrecchia (1991) examine a single-firm, imperfect competition setting comprised of informed traders, uninformed market makers (or investors), and liquidity traders. They find that large, risk neutral traders are unwilling to all hold shares in the economy because they anticipate an adverse selection problem in secondary-share markets: in other words, if they are required to sell their shares in response to a liquidity shock, they risk being confused with informed traders who sell in response to unfavorable information. As information asymmetry in the secondary market increases, large traders choose to hold fewer shares; this, in turn, increases the risk that must be borne by small investors, and hence lowers

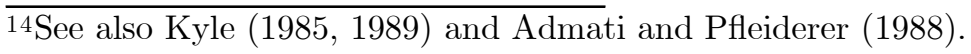


the equilibrium price of the firm. Equivalently, the firm's cost of capital rises. This suggests a path for future research: combining the variety of information structures analyzed here with imperfect competition settings to study how (or whether) average precision and information asymmetry interact in determining a firm's cost of capital. 


\section{APPENDIX}

\section{Proof of Proposition 1}

From eqn. (2), investor $i$ 's demand for shares of firms (in vector format) is

$$
\mathbf{X}_{i}=\tau \boldsymbol{\Pi}_{i}\left(E_{i}[\tilde{\mathbf{V}}]-\mathbf{P}\left(1+R_{f}\right)\right)
$$

Summing the demand function across investors yields

$$
\mathbf{X}_{0}=\sum_{i=1}^{N} \mathbf{X}_{i}=\tau \sum_{i=1}^{N} \boldsymbol{\Pi}_{i}\left(E_{i}[\tilde{\mathbf{V}}]-\mathbf{P}\left(1+R_{f}\right)\right) ;
$$

recall that $\mathbf{X}_{0}$ is the aggregate supply vector. Solving for $\mathbf{P}$, the vector of firm share prices, yields

$$
\mathbf{P}=\frac{\left(\boldsymbol{\Pi}_{0}\right)^{-1} \sum_{i=1}^{N} \boldsymbol{\Pi}_{i} E_{i}[\tilde{\mathbf{V}}]-\left(\frac{1}{N} \boldsymbol{\Pi}_{0}\right)^{-1} \frac{\mathbf{X}_{0}}{N \tau}}{1+R_{f}}
$$

Q.E.D.

\section{Proof of Proposition 2}

First, we re-express $\mathbf{P}$ as characterized in Proposition 1 as follows:

$$
\mathbf{P}=\left(\frac{1}{N} \boldsymbol{\Pi}_{0}\right)^{-1} \frac{\frac{1}{N} \sum_{i=1}^{N} \boldsymbol{\Pi}_{i} E_{i}[\tilde{\mathbf{V}}]-\frac{\mathbf{X}_{0}}{N \tau}}{1+R_{f}} .
$$

Next, substitute into this expression for $\mathbf{P}$ the characterization of $E_{i}[\tilde{\mathbf{V}}]$ :

$$
\begin{aligned}
\mathbf{P} & =\left(\frac{1}{N} \boldsymbol{\Pi}_{0}\right)^{-1} \frac{\frac{1}{N} \sum_{i=1}^{N} \boldsymbol{\Pi}_{i}\left(\boldsymbol{\Pi}_{i}^{-1}\left(\mathbf{\Psi} \mathbf{m}+\boldsymbol{\eta} \mathbf{y}+\mathbf{S}_{i} \mathbf{z}_{i}+\boldsymbol{\theta} \mathbf{u}\right)\right)-\frac{\mathbf{x}_{0}}{N \tau}}{1+R_{f}} \\
& =\left(\frac{1}{N} \boldsymbol{\Pi}_{0}\right)^{-1} \frac{\mathbf{\Psi m}+\boldsymbol{\eta} \mathbf{y}+\frac{1}{N} \sum_{i=1}^{N} \mathbf{S}_{i} \mathbf{z}_{i}+\boldsymbol{\theta} \mathbf{u}-\frac{\mathbf{x}_{0}}{N \tau}}{1+R_{f}}
\end{aligned}
$$

Thus, when investors condition their expectations over $\mathbf{P}$, they interpret $\mathbf{P}$ as a random variable characterized as

$$
\tilde{\mathbf{P}}=\left(\frac{1}{N} \boldsymbol{\Pi}_{0}\right)^{-1} \frac{\boldsymbol{\Psi} \mathbf{m}+\boldsymbol{\eta} \tilde{\mathbf{y}}+\frac{1}{N} \sum_{i=1}^{N} \mathbf{S}_{i} \tilde{\mathbf{z}}_{i}+\boldsymbol{\theta} \tilde{\mathbf{u}}-\frac{1}{\tau} \tilde{\mathbf{x}}_{0}}{1+R_{f}},
$$


where for convenience we now express the aggregate supply on a per-capita basis: that is, $\tilde{\mathbf{x}}_{0}=\frac{\tilde{\mathbf{x}}_{0}}{N}$. The law of large numbers implies that $\frac{1}{N} \sum_{i=1}^{N} \mathbf{S}_{i} \tilde{\mathbf{z}}_{i}$ converges to $\frac{1}{N} \sum_{i=1}^{N} \mathbf{S}_{i} \tilde{\mathbf{V}}$ because the idiosyncratic elements in $\tilde{\mathbf{z}}_{i}$ average out. Thus, we substitute this into eqn. (A2), along with the expression for $\tilde{\mathbf{u}}$ :

$$
\begin{aligned}
\tilde{\mathbf{P}} & =\left(\frac{1}{N} \boldsymbol{\Pi}_{0}\right)^{-1} \frac{\boldsymbol{\Psi} \mathbf{m}+\boldsymbol{\eta} \tilde{\mathbf{y}}+\frac{1}{N} \sum_{i=1}^{N} \mathbf{S}_{i} \tilde{\mathbf{V}}+\boldsymbol{\theta}\left(\tilde{\mathbf{V}}-\mathbf{b}^{-1} \mathbf{d}\left(\tilde{\mathbf{x}}_{0}-\overline{\mathbf{x}}_{0}\right)\right)-\frac{1}{\tau} \tilde{\mathbf{x}}_{0}}{1+R_{f}} \\
& =\left(\frac{1}{N} \boldsymbol{\Pi}_{0}\right)^{-1} \frac{\boldsymbol{\Psi} \mathbf{m}+\boldsymbol{\eta} \tilde{\mathbf{y}}+\left(\boldsymbol{\theta}+\frac{1}{N} \sum_{i=1}^{N} \mathbf{S}_{i}\right) \tilde{\mathbf{V}}-\left(\boldsymbol{\theta} \mathbf{b}^{-1} \mathbf{d}+\frac{\mathbf{I}}{\tau}\right) \tilde{\mathbf{x}}_{0}+\boldsymbol{\theta} \mathbf{b}^{-1} \mathbf{d} \overline{\mathbf{x}}_{0}}{1+R_{f}} .
\end{aligned}
$$

Now recall that investors conjecture that $\tilde{\mathbf{P}}$ is of the form $\tilde{\mathbf{P}}=\mathbf{a}+\mathbf{b} \tilde{\mathbf{V}}+\mathbf{c} \tilde{\mathbf{y}}-\mathbf{d} \tilde{\mathbf{x}}_{0}+\mathbf{e} \overline{\mathbf{x}}_{0}$. For this conjecture to be self-fulfilling, it must be the case that

$$
\begin{aligned}
& \mathbf{b}=\frac{\left(\frac{1}{N} \Pi_{0}\right)^{-1}}{1+R_{f}}\left(\left(\boldsymbol{\theta}+\frac{1}{N} \sum_{i=1}^{N} \mathbf{S}\right),\right. \text { and } \\
& \mathbf{d}=\frac{\left(\frac{1}{N} \boldsymbol{\Pi}_{0}\right)^{-1}}{1+R_{f}}\left(\boldsymbol{\theta} \mathbf{b}^{-1} \mathbf{d}+\frac{1}{\tau} \mathbf{I}\right) .
\end{aligned}
$$

Thus,

$$
\begin{aligned}
\mathbf{b}^{-1} \mathbf{d} & =\left(\boldsymbol{\theta}+\frac{1}{N} \sum_{i=1}^{N} \mathbf{S}_{i}\right)^{-1}\left(\frac{1}{N} \boldsymbol{\Pi}_{0}\right)\left(\frac{1}{N} \boldsymbol{\Pi}_{0}\right)^{-1}\left(\boldsymbol{\theta} \mathbf{b}^{-1} \mathbf{d}+\frac{1}{\tau} \mathbf{I}\right) \\
& =\left(\boldsymbol{\theta}+\frac{1}{N} \sum_{i=1}^{N} \mathbf{S}_{i}\right)^{-1}\left(\boldsymbol{\theta} \mathbf{b}^{-1} \mathbf{d}+\frac{1}{\tau} \mathbf{I}\right) .
\end{aligned}
$$

Hence, we can solve to get

$$
\mathbf{b}^{-1} \mathbf{d}=\frac{1}{\tau}\left(\frac{1}{N} \sum_{i=1}^{N} \mathbf{S}_{i}\right)^{-1}
$$

Substituting this expression for $\mathbf{b}^{-1} \mathbf{d}$ back into the expression for the precision of the orthogonal information in price, $\boldsymbol{\theta}$, yields

$$
\boldsymbol{\theta}=\tau^{2}\left[\frac{1}{N} \sum_{i=1}^{N} \mathbf{S}_{i}\right] \cdot \mathbf{W} \cdot\left[\frac{1}{N} \sum_{i=1}^{N} \mathbf{S}_{i}\right]^{\prime} .
$$

Q.E.D. 


\section{Proof of Proposition 3}

The average precision of investors' information is $\frac{N_{1}}{N}\left(\boldsymbol{\Psi}+Q_{1} \boldsymbol{\eta}+\boldsymbol{\theta}\right)+\frac{N_{2}}{N}\left(\boldsymbol{\Psi}+Q_{1} \boldsymbol{\eta}+Q_{2} \mathbf{S}\right)$.

It remains to solve for $\boldsymbol{\theta}$, the precision of the incremental information provided by price, $\tilde{u}$. Re-arranging eqn. (3) gives

$$
\mathbf{P}=\frac{\boldsymbol{\Pi}_{0}^{-1}}{1+R_{f}}\left[\sum_{i=1}^{N} \boldsymbol{\Pi}_{i} E_{i}\left[\tilde{\mathbf{V}} \mid \Phi_{i}\right]-\frac{N}{\tau} \tilde{\mathbf{x}}_{0}\right] .
$$

For the less informed group, $\boldsymbol{\Pi}_{1} E_{1}[\tilde{\mathbf{V}}]=\boldsymbol{\Pi}_{1}\left[\boldsymbol{\Pi}_{1}\right]^{-1}[\Psi \mathbf{m}+\boldsymbol{\eta} \mathbf{Y}+\boldsymbol{\theta} \mathbf{u}]=[\Psi \mathbf{m}+\boldsymbol{\eta} \mathbf{Y}+\boldsymbol{\theta u}]$.

Similarly, for the informed group, $\boldsymbol{\Pi}_{2} E_{2}[\tilde{\mathbf{V}}]=\boldsymbol{\Pi}_{2}\left[\boldsymbol{\Pi}_{2}\right]^{-1}[\mathbf{\Psi m}+\boldsymbol{\eta} \mathbf{Y}+\mathbf{S Z}]=[\mathbf{\Psi m}+\boldsymbol{\eta} \mathbf{Y}+\mathbf{S Z}]$.

Substituting into the price equation yields

$$
\begin{aligned}
\mathbf{P} & =\frac{\boldsymbol{\Pi}_{0}^{-1}}{1+R_{f}}\left[N_{1}[\mathbf{\Psi m}+\boldsymbol{\eta} \mathbf{Y}+\boldsymbol{\theta} \mathbf{u}]+N_{2}[\mathbf{\Psi m}+\boldsymbol{\eta} \mathbf{Y}+\mathbf{S Z}]-\frac{N}{\tau} \tilde{\mathbf{x}}_{0}\right] \\
& =\frac{\boldsymbol{\Pi}_{0}^{-1}}{1+R_{f}}\left[\left(N_{1}+N_{2}\right)[\mathbf{\Psi m}+\boldsymbol{\eta} \mathbf{Y}]+N_{1} \boldsymbol{\theta} \mathbf{u}+N_{2} \mathbf{S Z}-\frac{N}{\tau} \tilde{\mathbf{x}}_{0}\right] .
\end{aligned}
$$

Substituting $\tilde{\mathbf{u}}=\frac{\mathbf{b}^{-1}}{Q_{2}}\left[\tilde{\mathbf{P}}-\mathbf{a}-\mathbf{c} \tilde{\mathbf{Y}}+\overline{\mathbf{x}}_{0}(\mathbf{d}-\mathbf{e})\right]=\frac{\tilde{\mathbf{z}}}{Q_{2}}-\frac{\mathbf{b}^{-1} \mathbf{d}}{Q_{2}}\left(\tilde{\mathbf{x}}_{0}-\overline{\mathbf{x}}_{0}\right)$ implies

$$
\begin{aligned}
\mathbf{P} & =\frac{\boldsymbol{\Pi}_{0}^{-1}}{1+R_{f}}\left[\left(N_{1}+N_{2}\right)[\mathbf{\Psi m}+\boldsymbol{\eta} \mathbf{Y}]+N_{1} \boldsymbol{\theta}\left[\frac{\tilde{\mathbf{Z}}}{Q_{2}}-\frac{\mathbf{b}^{-1} \mathbf{d}}{Q_{2}}\left(\tilde{\mathbf{x}}_{0}-\overline{\mathbf{x}}_{0}\right)\right]+N_{2} \mathbf{S Z}-\frac{N}{\tau} \tilde{\mathbf{x}}_{0}\right] \\
& =\frac{\boldsymbol{\Pi}_{0}^{-1}}{1+R_{f}}\left[\left(N_{1}+N_{2}\right)[\mathbf{\Psi m}+\boldsymbol{\eta} \mathbf{Y}]+\left[\frac{N_{1} \boldsymbol{\theta}}{Q_{2}}+N_{2} \mathbf{S}\right] \mathbf{Z}-\left[N_{1} \boldsymbol{\theta} \frac{\mathbf{b}^{-1} \mathbf{d}}{Q_{2}}-\frac{N \mathbf{I}}{\tau}\right] \tilde{\mathbf{x}}_{0}+N_{1} \boldsymbol{\theta} \frac{\mathbf{b}^{-1} \mathbf{d}}{Q_{2}} \overline{\mathbf{x}}_{0}\right] .
\end{aligned}
$$

But recall once again that price is also equal to $\mathbf{P}=\mathbf{a}+\mathbf{b} \tilde{\mathbf{Z}}+\mathbf{c} \tilde{\mathbf{Y}}+\mathbf{d x}_{0}-\mathbf{e x}_{0}$.

Equating coefficients yields $\mathbf{b}=\frac{\Pi_{0}^{-1}}{1+R_{f}}\left[\frac{N_{1} \boldsymbol{\theta}}{Q_{2}}+N_{2} \mathbf{S}\right]$ and $\mathbf{d}=\frac{\Pi_{0}^{-1}}{1+R_{f}}\left[N_{1} \boldsymbol{\theta} \frac{\mathbf{b}^{-1} \mathbf{d}}{Q_{2}}-\frac{N \mathbf{I}}{\tau}\right]$.

Together these imply

$$
\mathbf{b}^{-1} \mathbf{d}=\frac{N}{N_{2} \tau} \mathbf{S}^{-1},
$$

where $N \equiv N_{1}+N_{2}$. This implies that the covariance matrix of $\tilde{\mathbf{u}}$, the error in the estimate of the vector of cash flows $\tilde{\mathbf{V}}$, is

$$
\frac{Q_{2} \mathbf{S}^{-1}}{Q_{2}^{2}}+\frac{1}{Q_{2}^{2}}\left(\mathbf{b}^{-1} \mathbf{d}\right) \mathbf{W}^{-1}\left(\mathbf{b}^{-1} \mathbf{d}\right)^{\prime}=\frac{\mathbf{S}^{-1}}{Q_{2}}+\frac{1}{Q_{2}^{2}}\left(\frac{N}{N_{2} \tau}\right)^{2}\left(\mathbf{S}^{-1}\right) \mathbf{W}^{-1}\left(\mathbf{S}^{-1}\right)^{\prime} .
$$


The precision matrix $\boldsymbol{\theta}$ is the inverse of this expression. Q.E.D.

\section{Proof of Corollary 2.}

Recall that the cost of capital is decreasing in $\operatorname{Avg}[\Pi]$, where

$$
A v g[\Pi]=\Psi+Q_{1} s+\frac{N_{1}}{N} \theta+\frac{N_{2}}{N} Q_{2} s=\Psi+(1-\alpha) Q s+\mu \alpha Q s+(1-\mu) \theta,
$$

and

$$
\theta=\left(\frac{1}{Q_{2} s}+\left(\frac{1}{\frac{N_{2}}{N} \tau s}\right)^{2} \frac{1}{Q_{2}^{2} w}\right)^{-1}=\left(\frac{1}{\alpha Q s}+\frac{1}{\mu^{2} \tau^{2} s^{2}} \frac{1}{\alpha^{2} Q^{2} w}\right)^{-1} .
$$

a. To prove a) note first that

$$
\frac{\partial \theta}{\partial \alpha}=Q s \frac{1}{\left(1+Q^{-1} s^{-1} w^{-1} \alpha^{-1} \tau^{-2} \mu^{-2}\right)^{2}}\left(1+2 Q^{-1} s^{-1} w^{-1} \alpha^{-1} \tau^{-2} \mu^{-2}\right) ;
$$

this implies that

$$
\begin{aligned}
\frac{\partial A v g[\Pi]}{\partial \alpha} & =(1-\mu)\left(-Q s+\frac{\partial \theta}{\partial \alpha}\right) \\
& =(1-\mu)\left(-Q s+Q s \frac{1}{\left(1+Q^{-1} s^{-1} w^{-1} \alpha^{-1} \tau^{-2} \mu^{-2}\right)^{2}}\left(1+2 Q^{-1} s^{-1} w^{-1} \alpha^{-1} \tau^{-2} \mu^{-2}\right)\right) \\
& =-\frac{(1-\mu) Q s}{\left(Q s w \alpha \tau^{2} \mu^{2}+1\right)^{2}}<0 .
\end{aligned}
$$

Therefore, $\operatorname{Avg}[\Pi]$ is decreasing in $\alpha$, which makes it increasing in $(1-\alpha)$.

b. The fact that the private information of informed investors is more precise than the less informed investors' imperfect inference of their information through price implies $\alpha Q s-\theta>0$. It is also straightforward to show $\frac{\partial \theta}{\partial \mu}>0$. Together these imply

$$
\frac{\partial A v g[\Pi]}{\partial \mu}=\alpha Q s-\theta+(1-\mu) \frac{\partial \theta}{\partial \mu}>0 .
$$

c. $\frac{\partial A v g[\Pi]}{\partial Q_{1}}=s>0$.

d. Note that $\frac{\partial \theta}{\partial Q_{2}}>0$; thus

$$
\frac{\partial A v g[\Pi]}{\partial Q_{2}}=\frac{N_{1}}{N} \frac{\partial \theta}{\partial Q_{2}}+\frac{N_{2}}{N} s>0 .
$$


Q.E.D.

\section{Proof of Proposition 4.}

Let $\Pi$ represent investors' homogeneous, total precision matrix. From the proof to Proposition 2, we know that investors' precision is additive in the precision of public information about firms' cash flows (additive in $\boldsymbol{\eta}$ ). Without loss of generality, assume that firm 1 discloses additional information about its cash flow with error $\tilde{\delta}$, and $\tilde{\delta}$ is independent of all other variables. Let $\Pi^{*}$ represent investors' homogeneous, total precision matrix that results from firm 1's additional disclosure, and Cov$^{*}$ its inverse: that is, $\mathbf{C o v}^{*}=\mathbf{\Pi}^{*-1}$. With firm 1's additional disclosure, investors' precision matrix about firms' cash flows becomes

$$
\Pi^{*}=\Pi+\left(\begin{array}{llll}
\operatorname{Var}\left[\tilde{\delta}_{j}\right] & 0 & \ldots & 0 \\
0 & 0 & \ldots & 0 \\
\cdot & . & . & . \\
0 & 0 & \ldots & 0
\end{array}\right)^{-1}=\left(\begin{array}{llll}
\Pi_{1,1}+\operatorname{Var}\left[\tilde{\delta}_{j}\right]^{-1} & \Pi_{1,2} & \ldots & \Pi_{1, J} \\
\Pi_{2,1} & \Pi_{2,2} & \ldots & \Pi_{2, J} \\
\cdot & . & . & . \\
\Pi_{J, 1} & \Pi_{J, 2} & \ldots & \Pi_{J, J}
\end{array}\right),
$$

where $\Pi_{j, k}$ represents the $j$-th, $k$-th element of the matrix $\Pi$, and

$$
\operatorname{Cov}^{*}=\left(\begin{array}{llll}
\Pi_{1,1}+\operatorname{Var}\left[\tilde{\delta}_{j}\right]^{-1} & \Pi_{1,2} & \ldots & \Pi_{1, J} \\
\Pi_{2,1} & \Pi_{2,2} & \ldots & \Pi_{2, J} \\
\cdot & \cdot & \cdot & \cdot \\
\Pi_{J, 1} & \Pi_{J, 2} & \ldots & \Pi_{J, J}
\end{array}\right)^{-1}
$$

Let $\operatorname{Cov}_{j, k}^{*}$ and $\Pi_{j, k}^{*}$ represent the $j$-th, $k$-th element of the matrices $\mathbf{C o v}^{*}$ and $\boldsymbol{\Pi}^{*}$, respectively. Then

$$
\begin{aligned}
\operatorname{Cov}_{1, j}^{*} & =\frac{\text { Cofactor }_{j, 1} \text { of } \boldsymbol{\Pi}^{*} \text { matrix }}{\text { Determinant of } \boldsymbol{\Pi}^{*} \text { matrix }} \\
& =\frac{\text { Cofactor } j, 1 \text { of } \boldsymbol{\Pi}^{*} \text { matrix }}{\sum_{k=1}^{J} \Pi_{1, k}^{*} \cdot \text { Cofactor }_{1, k} \text { of } \boldsymbol{\Pi}^{*} \text { matrix }}
\end{aligned}
$$




$$
\begin{aligned}
& \text { Cofactor }_{j, 1} \text { of } \boldsymbol{\Pi} \text { matrix } \\
& =\overline{\Pi_{1,1}^{*} \cdot \text { Cofactor }_{1,1} \text { of } \Pi^{*} \text { matrix }+\sum_{k=2}^{J} \Pi_{1, k}^{*} \cdot \text { Cofactor }_{1, k} \text { of } \Pi^{*} \text { matrix }} \\
& =\frac{\text { Cofactor }_{j, 1} \text { of } \Pi \text { matrix }}{\operatorname{Var}\left[\tilde{\delta}_{j}\right]^{-1} \cdot \text { Cofactor }_{1,1} \text { of } \Pi \text { matrix }+\sum_{k=1}^{J} \Pi_{1, k} \cdot \text { Cofactor }_{1, k} \text { of } \Pi \text { matrix }} \\
& \text { Cofactor }_{j, 1} \text { of } \boldsymbol{\Pi} \text { matrix }
\end{aligned}
$$

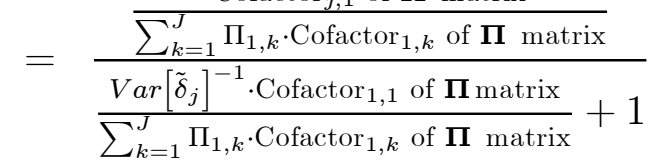

$$
\begin{aligned}
& =\frac{\operatorname{Var}\left[\tilde{\delta}_{j}\right]}{\operatorname{Cov}{ }_{1,1}+\operatorname{Var}\left[\tilde{\delta}_{j}\right]} \operatorname{Cov}_{1, j} \\
& =\frac{\operatorname{Var}\left[\tilde{\delta}_{j}\right]}{\operatorname{Var}\left[\tilde{V}_{1}\right]+\operatorname{Var}\left[\tilde{\delta}_{j}\right]} \operatorname{Cov}_{1, j} .
\end{aligned}
$$

Q.E.D. 
Admati, A., 1985, A Noisy Rational Expectations Equilibrium for Multi-Asset Security Markets, Econometrica 53, 629-658.

Admati, A., and P. Pfleiderer, 1988, A Theory of Intraday Patterns: Volume and Price Variability, Review of Financial Studies 1, 3-40.

Amihud, Y., and H. Mendelson, 1986, The Effects of Beta, Bid-Ask Spread, Residual Risk and Size on Stock Returns, Journal of Finance, 479-486.

Association for Investment Management and Research (AIMR), 2001, Analysts, Portfolio Managers say Volume, Quality of information have fallen under Regulation FD AIMR member survey shows, http://www.aimr.org/pressroom/01releases/regFD_survey.html.

Barry, C., and S. Brown, 1984, Differential information and the Small Firm Effect, Journal of Financial Economics 13, 283-294.

Barry, C., and S. Brown, 1985, Differential Information and Security Market Equilibrium, Journal of Financial and Quantitative Analysis 20, 407-422.

Barth, M., Y. Konchitchki, and W. Landsman, 2006, Cost of capital and financial statement transparency, Working paper, Stanford University and University of North Carolina.

Botosan, C., and M. Plumlee, 2003, Are Information Attributes Priced? Working paper, University of Utah.

Botosan, C., M. Plumlee, and Y. Xie, 2004, The Role of Information Precision in Determining Cost-of-equity-capital, Review of Accounting Studies 9, 197-228.

Brown, S., 1979, The Effect of Estimation Risk on Capital Market Equilibrium, Journal of Financial and Quantitative Analysis 15, 215-220. 
Chen, S., T. Shevlin, and Y. Tong. 2007, Does the pricing of financial reporting quality change around dividend changes? Journal of Accounting Research 45, 1-40.

Chordia, T., R. Roll, and A. Subrahmanyam, 2000, Commonality in Liquidity, Journal of Financial Economics 56, 3-28.

Cohen, D., 2008, Does Information Risk Really Matter? An Analysis of the Determinants and Economic Consequences of Financial Reporting Quality, Asia Pacific Journal of Accounting and Economics 15, 69-90.

Copeland, T., and D. Galai, 1983, Information Effects on the Bid-Ask Spread, Journal of Finance 38, 1457-1469.

Core, J., W. Guay, and R. Verdi, 2008, Is Accruals Quality a Priced Risk Factor?, Journal of Accounting and Economics 46, 2-22.

Diamond, D., and R. Verrecchia, 1981, Information Aggregation in a Noisy Rational Expectations Economy, Journal of Financial Economics 9, 221-235.

Diamond, D., and R. Verrecchia, 1991, Disclosure, Liquidity and the Cost of Capital, Journal of Finance 46, 1325-1359.

Dhaliwal, D., Z. Chen, and H. Xie, 2006, Regulation Fair Disclosure and the Cost of Equity Capital, Working paper.

Duarte, J., X. Han, J. Harford, and L. Young, 2006, Information Asymmetry, Information Dissemination and the Effect of Regulation FD on the Cost of Capital, Journal of Financial Economics, forthcoming.

Easley, D., and M. O'Hara, 2004, Information and the Cost of Capital, Journal of Finance 59, 1553-1583. 
Easley, D, S. Hvidkjaer, and M. O'Hara, 2002, Is information risk a determinant of asset returns?, Journal of Finance 57, 2185-2222.

Fama, E., 1976, Foundations of Finance, Basic Books, New York.

Francis, J., LaFond, R., Olsson, P., and Schipper, K., 2005, The Market Pricing of Accruals Quality, Journal of Accounting and Economics 39, 295-327.

Gao, P., 2008, Disclosure Quality, Cost of Capital, and Investor Welfare, Working paper, University of Chicago.

Glosten, L. and P. Milgrom, 1985, Bid, Ask, and Transaction Prices in a Specialist Market with Hetergeneously Informed Traders, Journal of Financial Economics 14, $71-100$.

Gomes, A., G. Gorton, and L. Madureira, 2006, SEC Regulation Fair Disclosure, Information, and the Cost of Capital, Working Paper: Washington University; University of Pennsylvania; Case Western Reserve University.

Grossman, S., 1976, Efficiency of Competitive Stock Markets Where Traders Have Diverse Information, Journal of Finance 31, 573-585.

Grossman, S., and J. Stiglitz, 1980, On the impossibility of informationally efficient markets, American Economic Review 70, 393-408.

Healy, P., and K. Palepu, 2001, Information Asymmetry, Corporate Disclosure, and the Capital Markets: A Review of the Empirical Disclosure Literature, Journal of Accounting and Economics 31, 405-440.

Hellwig, M., 1980, On the Aggregation of Information in Competitive Markets, Journal of Economic Theory 22, 477-498. 
Hughes, J., J. Liu, and J. Liu, 2007, Information, Diversification and the Cost of Capital, The Accounting Review 82, 705-729.

Kim, O., and R. Verrecchia, 1991, Market Reactions to Anticipated Announcements, Journal of Financial Economics 30, 273-309.

Kravet, T. D., and T. J. Shevlin, 2007, Accounting restatements and information risk, Working Paper, University of Washington.

Kyle, A., 1985, Continuous Auctions and Insider Trade, Econometrica 53, 1315-1335.

Kyle, A., 1989, Informed Speculation with Imperfect Competition, Review of Economic Studies 56, 317-356.

Lambert, R., Leuz, C., and R. Verrecchia, 2007, Accounting Information, Disclosure, and the Cost of Capital, Journal of Accounting Research 45, 385-420.

Leland, H., 1992, Insider Trading: Should It Be Prohibited?, The Journal of Political Economy 100, 859-887.

Leuz, C., and P. Wysocki, 2008, Economic Consequences of Financial Reporting and Disclosure Regulation: A Review and Suggestions for Future Research, Working paper.

Levitt, A., 1998, The Importance of High Quality Accounting Standards, Accounting Horizons 12, 79-82.

Lintner, J., 1965, The Valuation of Risk Assets and the Selection of Risky Investments in Stock Portfolios and Capital Budgets, Review of Economics \& Statistics 65, 13-37. Lintner, J., 1969, The Aggregation of Investors' Diverse Judgments and Preferences in Purely Competitive Security Markets, Journal of Financial and Quantitative Analysis 
4, 347-400.

Loss, L., 1983, Fundamentals of Securities Regulation (Little Brown and Company; Boston).

Liu, M., and P. Wysocki, 2007, Cross-sectional Determinants of Information Quality Proxies and Cost of Capital, Working Paper.

Loss, L., and Seligman, J., 2001, Fundamentals of Securities Regulation, 4th edition. Gaithersburg, MD: Aspen Law \& Business, 2001.

Merton, R., 1987, A Simple Model of Capital Market Equilibrium With Incomplete Information, Journal of Finance 43, 483-510.

Mohanram, P., and S. Rajgopal, 2008, Is PIN priced risk?, Journal of Accounting and Economics, forthcoming.

Nichols, D., 2006, Fundamental risk or information risk? An analysis of the residual accrual volatility factor, Working Paper, Cornell University.

Ogneva, M., 2008, Accrual Quality and Expected Returns: The Importance of Controlling for Cash Flow Shocks, Working Paper, Stanford University.

O'Hara, M., 2003, Presidential Address: Liquidity and Price Discovery, Journal of Finance 58, 1335-1354.

Securities and Exchange Commission (SEC), 2000, Final Rule: Selective Disclosure and Insider Trading, Exchange Act Release No. 33-7881 (Oct. 23, 2000), htt://www.sec.gov/rules/final/33-7881.htm.

Sharpe, W., 1964, Capital Asset Prices, A Theory of Market Equilibrium Under Conditions of Risk, Journal of Finance 19, 425-442. 
Unger, L., 2000, Speech by SEC Commissioner: Fallout from Regulation FD - Has the SEC Finally Cut the Tightrope?

Verdi, R., 2005, Information Environment and the Cost of Capital, Working paper, MIT.

Wang, J., 1993, A Model of Intertemporal Asset Pricing under Asymmetric Information, The Review of Economic Studies 60, 249-282. 